\title{
Gastrodin Protects Apoptotic Dopaminergic Neurons in a Toxin-Induced Parkinson's Disease Model
}

\author{
Hemant Kumar, In-Su Kim, Sandeep Vasant More, Byung-Wook Kim, \\ Young-Yil Bahk, and Dong-Kug Choi
}

Department of Biotechnology, Konkuk University, Chungju 380-701, Republic of Korea

Correspondence should be addressed to Dong-Kug Choi; choidk@kku.ac.kr

Received 19 November 2012; Revised 4 January 2013; Accepted 9 January 2013

Academic Editor: Youn Chul Kim

Copyright (C) 2013 Hemant Kumar et al. This is an open access article distributed under the Creative Commons Attribution License, which permits unrestricted use, distribution, and reproduction in any medium, provided the original work is properly cited.

\begin{abstract}
Gastrodia elata (GE) Blume is one of the most important traditional plants in Oriental countries and has been used for centuries to improve various conditions. The phenolic glucoside gastrodin is an active constituent of GE. The aim of this study was to investigate the neuroprotective role of gastrodin in 1-methyl-4-phenylpyridinium ( $\left.\mathrm{MPP}^{+}\right) / 1$-methyl-4-phenyl-1,2,3,6-tetrahydropyridine(MPTP) induced human dopaminergic SH-SY5Y cells and mouse model of Parkinson's disease (PD), respectively. Gastrodin significantly and dose dependently protected dopaminergic neurons against neurotoxicity through regulating free radicals, Bax/Bcl-

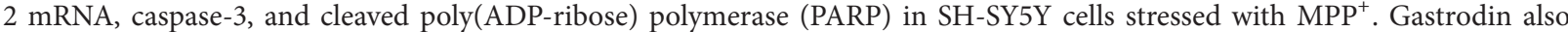
showed neuroprotective effects in the subchronic MPTP mouse PD model by ameliorating bradykinesia and motor impairment in the pole and rotarod tests, respectively. Consistent with this finding, gastrodin prevented dopamine depletion and reduced reactive astrogliosis caused by MPTP as assessed by immunohistochemistry and immunoblotting in the substantiae nigrae and striatata of mice. Moreover, gastrodin was also effective in preventing neuronal apoptosis by attenuating antioxidant and antiapoptotic activities in these brain areas. These results strongly suggest that gastrodin has protective effects in experimental PD models and that it may be developed as a clinical candidate to ameliorate PD symptoms.
\end{abstract}

\section{Introduction}

Parkinson's disease (PD) is neurodegenerative disorder characterized by progressive loss of dopaminergic neurons in the pars compacta of the substantia nigra (SNpC), which leads to clinical symptoms of rigidity, resting tremor, and bradykinesia $[1,2]$. 1-Methyl-4-phenyl-1,2,3,6-tetrahydropyridine (MPTP) is a known mitochondrial complex I inhibitor that selectively damages dopaminergic neurons in the SNpC and leads to the depletion of dopamine in the striatum resulting in parkinsonian syndrome $[1,3,4]$. Following parenteral administration, MPTP enters the brain and is metabolized to 1-methyl-4-phenylpyridinium $\left(\mathrm{MPP}^{+}\right)$by monoamine oxidase- $B$, which induces neuronal cell death [5]. The subchronic MPTP mouse model is quite a popular regimen, as it causes apoptosis and depletes striatal dopamine by $40-50 \%$ in young adult C57BL/6 mice, and dopaminergic lesions stabilize within 21 days after MPTP administration $[6,7]$. Human dopaminergic SH-SY5Y cells possess many of the qualities of human neurons and, as such, have served as a well-established PD model $[8,9]$.

Synthetic drugs cause undesirable adverse effects, whereas natural products are considered safe and effective. Herbal medicines are becoming popular for improving quality of life with either limited or no side effects [10]. The influence of natural products is quite marked in drug discovery. Of 1,335 approved drugs from the 1940s to date, 59 (4\%) were derived from natural products, and 299 (22\%) were derived from a natural product (semisynthetic modification) [11]. The phenolic glucoside gastrodin is an active constituent of Gastrodia elata Blume (Orchidaceae) and is one of the most important traditional plants in Oriental countries. Gastrodin has been used to treat various ailments such as headache, dizziness, vertigo, and convulsive illnesses in traditional medicine. Apart from traditional claims, scientific reports support the antioxidative [12, 13], anticonvulsive [14], anti-inflammatory [15-17], antiepileptic [18], antiobesity [19], anxiolytic [20], and learning and memory improvements 
$[21,22]$ in activities of gastrodin. Gastrodin significantly attenuates the expression levels of neurotoxic proinflammatory mediators including inducible nitric oxide synthase, cyclooxygenase-2, and the proinflammatory cytokines tumor necrosis factor- $\alpha$ and interleukin- $1 \beta$ in lipopolysaccharidestimulated microglial cells $[17,23]$. Gastrodin is also a potent antioxidant and free radical scavenger that decreases the levels of lipid peroxidation [24] and increases the expression of genes encoding antioxidant proteins [25]. In addition, gastrodin has been used in clinics as an effective and safe drug for preventing neurocognitive decline following cardiopulmonary bypass [26] and is beneficial to older patients with refractory hypertension by improving the balance of endothelin and nitric oxide in plasma [27], suggesting safe use in humans.

However, studies evaluating the neuroprotective role of gastrodin in $\mathrm{MPP}^{+} / \mathrm{MPTP} \mathrm{PD}$ experimental models have not been conducted. In the present study, we elucidated the probable neuroprotective mechanism of gastrodin using in vitro and in vivo experimental models of $\mathrm{PD}$. SH-SY5Y cells were treated with $1 \mathrm{mM} \mathrm{MPP}{ }^{+}$and/or gastrodin (1, 5 , and $25 \mu \mathrm{M}$ ) and assessed for changes in cell morphology and cell viability. We further characterized antioxidant (reactive oxygen species (ROS) inhibition, superoxide dismutase (SOD) activity) and antiapoptotic activities (Bax/Bcl2 mRNA, caspase-3, and cleaved PARP) in SH-SY5Y cells stressed with $\mathrm{MPP}^{+}$to elucidate the neuroprotective effects of gastrodin. Furthermore, we used MPTP-intoxicated C57BL/6 mice and then carried out behavioral (pole and rotarod tests), antioxidant (SOD, heme oxygenase-1 (HO-1)), histochemical (tyrosine hydroxylase (TH) and glial fibrillary acidic protein (GFAP)), and histobiological evaluations (Bax, Bcl-2, cleaved poly(ADP-ribose) polymerase (PARP), and caspase3 activity). The present results reveal gastrodin as a potential candidate with neuroprotective and antiapoptotic activities and strongly suggest gastrodin as a clinical candidate for PD.

\section{Materials and Methods}

2.1. Reagents. Gastrodin was purchased from PhytoLab (Vestenbergsgreuth, Germany). $\mathrm{MPP}^{+}, \mathrm{MPTP}, 2$,2-azobis (2-amidinopropane) hydrochloride (AAPH), 1,1-diphenyl2-picrylhydrazyl (DPPH), (4-pyridyl-1-oxide)-N-tert-butylnitrone, 3-(3,4-dimethylthiazole-2-yl)-2,5-diphenyl-tetrazolium bromide (MTT), and a caspase- 3 assay kit were purchased from Sigma-Aldrich (St. Louis, MO, USA). The 10x RIPA buffer was obtained from Millipore (Milford, MA, USA). The protease inhibitor and phosphatase inhibitor cocktail tablets were supplied by Roche (Roche, Indianapolis, IN, USA). Tween 80 was purchased from Merck (Calbiochem, Darmstadt, Germany). Six-well and 96-well tissue culture plates and $100 \mathrm{~mm}$ culture dishes were purchased from Nunc Inc. (Aurora, IL, USA). Dulbecco's modified Eagle's medium (DMEM) and fetal bovine serum (FBS) were purchased from Gibco-BRL Technologies (Carlsbad, CA, USA). All other chemicals used in this study were of analytical grade and were obtained from Sigma Chemical Co.
2.2. Cell Culture and Treatments. Human dopaminergic SHSY5Y cells were obtained from the American Type Culture Collection (Manassas, VA, USA) and cultured in DMEM supplemented with $10 \%(\mathrm{v} / \mathrm{v})$ inactivated FBS, and $100 \mathrm{U} / \mathrm{mL}$ penicillin/streptomycin. The cells were maintained at $37^{\circ} \mathrm{C}$ in $5 \% \mathrm{CO}_{2}$ and a $95 \%$ humidified air incubator for the indicated time. All experiments were carried out $24-48 \mathrm{~h}$ after the cells were seeded. The cells were pretreated with various concentrations $(1,5$, and $25 \mu \mathrm{M})$ of gastrodin for $4 \mathrm{~h}$ before incubation in medium containing $1 \mathrm{mM} \mathrm{MPP}^{+}$. Control cells were treated with the same medium without drugs.

2.3. Animals and Treatments. Six-week-old male C57BL/6 mice were obtained from Samtako Bio Korea (Gyeonggido, Korea) and acclimatized before use. Mice $\sim 8$ weeks of age and $25-28 \mathrm{~g}$ in weight were used in the present study. All experiments were performed in accordance with the Principles of Laboratory Animal Care (NIH publication no. 85-23, revised 1985) and Guidelines for Animal Experiments at Konkuk University. The animals were housed in a controlled environment $\left(23 \pm 1^{\circ} \mathrm{C}\right.$ and $50 \% \pm 5 \%$ humidity) and allowed food and water ad libitum. The room lights were on between 8:00 h and 20:00 h; sixty animals were divided into five groups containing 12 animals each. The groups included vehicle, MPTP, $10 \mathrm{mg} / \mathrm{kg}$ gastrodin, $30 \mathrm{mg} / \mathrm{kg}$ gastrodin, and $60 \mathrm{mg} / \mathrm{kg}$ gastrodin. Gastrodin was administered perorally for 15 days at the respective doses, and MPTP was administered intraperitoneally for the last 5 days of gastrodin treatment. All groups except the vehicle group received an injection of $30 \mathrm{mg} / \mathrm{kg} /$ day MPTP for 5 days. MPTP and gastrodin were dissolved in saline and prepared just prior to dosing.

2.4. Assessment of Cell Viability. Cell viability was measured using the quantitative colorimetric MTT assay, which reveals mitochondrial activity of living cells, as described previously [28]. MTT dissolved in phosphate-buffered saline was added at the end of incubation to a final concentration of $0.5 \mathrm{mg} / \mathrm{mL}$. After $4 \mathrm{~h}$ incubation at $37^{\circ} \mathrm{C}$ and $5 \% \mathrm{CO}_{2}$, the supernatants were removed, and the formed formazan crystals in the viable cells were measured at $550 \mathrm{~nm}$ using a microplate reader (Molecular Devices, Sunnyvale, CA, USA).

2.5. Measurement of Free Radical Scavenging Activity, Intracellular Reactive Oxygen Species (ROS), and Superoxide Dismutase (SOD) Activity. Free radical scavenging activity was evaluated using an electron spin resonance (ESR) spectrometer (JEOL, Tokyo, Japan). DPPH radical scavenging activity was measured using a method described previously [29]. A sample solution of gastrodin was added to $60 \mu \mathrm{M}$ $\mathrm{DPPH}$ in methanol and incubated for $2 \mathrm{~min}$. Alkyl radicals were generated by AAPH. The reaction mixture, containing $10 \mathrm{mM}$ AAPH, $10 \mathrm{mM} 4-\mathrm{POBN}$, and gastrodin of various concentrations in $\mathrm{PBS}(\mathrm{pH} 7.4)$, was incubated at $37^{\circ} \mathrm{C}$ in a water bath for $30 \mathrm{~min}$. Hydroxyl radicals were generated by the iron-catalyzed Haber-Weiss reaction (Fenton-driven Haber-Weiss reaction), and the generated hydroxyl radicals reacted rapidly with nitrone spin-trap DMPO. The reaction 
mixture, containing $0.3 \mathrm{M}$ DMPO, $10 \mathrm{mM} \mathrm{FeSO}_{4}, 10 \mathrm{mM}$ $\mathrm{H}_{2} \mathrm{O}_{2}$, and various concentrations of gastrodin in PBS ( $\mathrm{pH} 7.2$ ), was incubated for $2.5 \mathrm{~min}$. Superoxide radicals were generated by an UV-irradiated riboflavin/EDTA system. The reaction mixture, containing $0.8 \mathrm{mM}$ riboflavin, 1.6 mM EDTA, 0.8 M DMPO, and various concentrations of gastrodin, was irradiated for 1 min under a UV lamp at $365 \mathrm{~nm}$. The ESR spectrum was recorded for each radical using an ESR spectrometer. The intracellular ROS production was measured using a nonfluorescent compound $2^{\prime}, 7^{\prime}$ dichlorofluorescein diacetate (DCFH-DA) in SH-SY5Y cells. It measures the formation of hydrogen peroxide generated by an oxidative metabolic burst. Viable cells can deacetylate DCFH-DA to $2^{\prime}, 7^{\prime}$-dichlorofluorescein (DCFH), which is not fluorescent. This compound reacts quantitatively with oxygen species within the cell to produce a fluorescent dye $2^{\prime}, 7^{\prime}$ dichlorofluorescein (DCF), which remains trapped within the cell and can be measured to provide an index of ROS level. After the drug treatment, cultures were washed with PBS, loaded with $20 \mu \mathrm{M}$ DCF-DA for $30 \mathrm{~min}$ at $37^{\circ} \mathrm{C}$, and then washed again with PBS. DCF fluorescence was analyzed using a fluorescence plate reader (Spectramax M2e, Molecular Devices) at excitation and emission wavelengths of 490 and $530 \mathrm{~nm}$. SOD was measured as an additional indicator of change in oxidative mechanism following treatment(s) in SH-SY5Y cells and tissue lysate. SOD was determined using Cayman chemical kit (Ann Arbor, MI, USA) as per the manufacturer's instructions.

2.6. Behavioral Testing: Pole and Rotarod Tests. The pole test for bradykinesia was conducted using a modification of a method reported previously [30]. The mice were positioned with the head up at the top of a rough-surfaced pole $(8 \mathrm{~mm}$ diameter and $55 \mathrm{~cm}$ height), and the T-turn and total locomotor activity (TLA) were measured. The T-turn is the time that the animal takes to completely turn his face downside. TLA is the time until the mouse arrives on the floor. The duration of these parameters reflects bradykinesia. This test was performed five times successively for each mouse, and the average was taken for analysis.

The rotarod test was performed as described previously [31] with slight modifications. One week after the last MPTP injection, rotarod performance was evaluated on the suspended rod of an accelerating rotarod apparatus (diameter: $3 \mathrm{~cm}$ ) that accelerates at a constant rate from 1 to $30 \mathrm{rpm}$ for $300 \mathrm{~s}$. Mice were trained for 3 consecutive days, and they were placed on the rod for five trials. Time was recorded for each trial. A trial ended when the mouse fell off the rotarod or after time had reached $300 \mathrm{~s}$. A resting time of $180 \mathrm{~s}$ was allowed between each trial.

2.7. Immunohistochemistry. Mice were anesthetized with sodium pentobarbital $(50 \mathrm{mg} / \mathrm{kg}$, i.p.) after performing the behavioral experiments and their brains were perfusionfixed with $4 \%$ paraformaldehyde in $0.1 \mathrm{M}$ phosphate buffer ( $\mathrm{pH}$ 7.4) following a saline flush as described previously [6]. The brains were removed after perfusion fixation at $4^{\circ} \mathrm{C}$ and immersed in the same fixative and dehydrated in
$30 \%$ sucrose solution until they were embedded in tissue freezing medium (Leica, Gmbh Heidelberger, Germany). Frozen sections $(30 \mu \mathrm{M})$ of the striatum and SNpC were used for immunohistochemistry as described previously [32]. Primary antibodies used for TH and GFAP were anti-TH rabbit antibody (1:1000; Calbiochem San Diego, CA, USA) and a rabbit polyclonal antibody to GFAP (1:5000; Abcam, Cambridge, UK), respectively. The TH immunohistochemistry sections were incubated with biotinylated anti-rabbit (Vector Laboratories, Burlingame, CA, USA) antibody for $1 \mathrm{~h}$, followed by incubation in the avidin-biotin-peroxidase complex Vectastain Elite ABC Kit (Vector Laboratories) for $60 \mathrm{~min}$ at room temperature, according to the supplier's recommendations. Last, the sections have reacted with the Vector DAB substrate kit (Vector Laboratories) for color development. The GFAP sections were incubated with rabbit antigoat GFAP antibody $(1: 200)$ (Alexa Flour 488, Invitrogen, Carlsbad, CA, USA) for $1 \mathrm{~h}$. Stained cells were viewed under a bright field microscope (Carl Zeiss Inc., Oberkochen, Germany).

2.8. Immunoblot Analysis. A $0.1 \mathrm{~mL}$ aliquot of RIPA buffer (1x PBS, 1\% NP-40, 0.5\% sodium deoxycholate, $0.1 \%$ SDS containing freshly added protease inhibitor cocktail (Calbiochem)) was added to cells cultured in $100 \mathrm{~mm}$ plates to obtain the total cell lysate. Cells were scraped, incubated for $10 \mathrm{~min}$ on ice, and centrifuged at $14,000 \times \mathrm{rpm}$ for $10 \mathrm{~min}$ at $4^{\circ} \mathrm{C}$. For the animal experiment, tissues were washed two times with PBS, placed at $4^{\circ} \mathrm{C}$, and homogenized using a $1 \mathrm{~mL}$ syringe in lysis buffer (1x RIPA lysis buffer, protease inhibitor cocktail, and phosphatase inhibitor cocktail) and then finally passed through a $31^{1 / 2}$ gauge syringe needle and centrifuged at $14,000 \mathrm{rpm}$ at $4^{\circ} \mathrm{C}$ for $15 \mathrm{~min}$. The supernatants were collected for further analysis. Protein concentration was determined by the Bio-Rad DC Protein Assay (Hercules, CA, USA). $15 \mu \mathrm{g}$ of whole cell lysates (cell experiments) or $40 \mu \mathrm{g}$ of protein (animal experiments) were separated electrophoretically by $10 \%$ sodium dodecyl sulfate-polyacrylamide electrophoresis (SDS-PAGE), and the resolved proteins were transferred to polyvinylidene difluoride membranes (Millipore, Bedford, MA, USA). The membranes were incubated for $1 \mathrm{~h}$ with $5 \%$ skimmed milk in PBS buffer to block nonspecific binding and then incubated with primary antibodies to anti-TH, anti-PARP $(1: 1000$; Cell Signaling Technology), anti-GFAP (1:30,000; Abcam), antiHO-1 (1:1000; Stressgen biotechnology), and anti- $\beta$-actin (1:2000; Cell Signaling Technology). The blots were visualized using the SuperSignal West Pico Chemiluminescent Substrate Detection System (Thermo Scientific, Rockford, IL, USA), according to the manufacturer's procedure. The optical densities of the antibody-specific bands were analyzed using a luminescent image analyzer, LAS-3000 (Fuji, Tokyo, Japan).

2.9. Total RNA Extraction and Reverse Transcription Polymerase Chain Reaction (RT-PCR). SH-SY5Y cells $\left(1 \times 10^{6}\right.$ cells/well) were cultured in 6-well plates, and total RNA was isolated by extraction with TRIzol (Invitrogen). Total RNA was also extracted from midbrain and striatal tissues using 


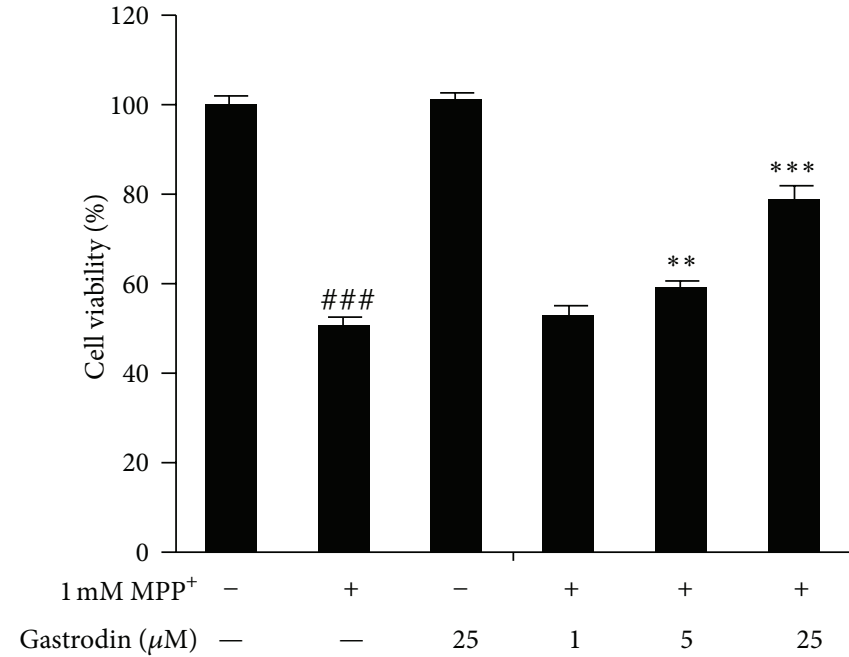

(A)

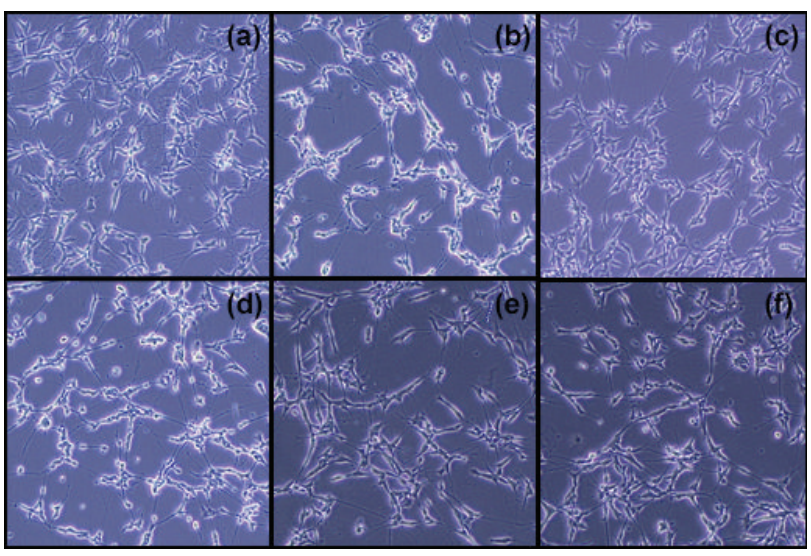

(B)

FIGURE 1: Effect of gastrodin on $\mathrm{MPP}^{+}$-induced neurotoxicity in the dopaminergic neuroblastoma SH-SY5Y cell line. Cells were exposed to gastrodin and $1 \mathrm{mM} \mathrm{MPP}{ }^{+}$for $48 \mathrm{~h}$. Cell viability (A) and morphology of SH-SY5Y cells (B) after treatment with control (a), $1 \mathrm{mM} \mathrm{MPP}{ }^{+}$ (b), $25 \mu \mathrm{M}$ gastrodin (c), $25 \mu \mathrm{M}$ gastrodin $+1 \mathrm{mM} \mathrm{MPP}^{+}$(d), $5 \mu \mathrm{M}$ gastrodin $+1 \mathrm{mM} \mathrm{MPP}^{+}(\mathrm{e})$, and $1 \mu \mathrm{M}$ gastrodin $+1 \mathrm{mM} \mathrm{MPP}^{+}(\mathrm{f})$. Data are percentages of values in the untreated control cultures and are means \pm standard errors of three independent experiments in triplicate. ${ }^{\# \# \#} P<0.001$ compared with the control group, ${ }^{* *} P<0.01$, and ${ }^{* * *} P<0.001$ compared with the $\mathrm{MPP}^{+}$-treated group (one-way analysis of variance followed by Tukey's post hoc test).

TRIzol reagent for RT-PCR. A total of $2.5 \mu \mathrm{g}$ of total RNA was reverse-transcribed using a First Strand cDNA Synthesis Kit (Invitrogen). PCR was performed using the above prepared cDNA as the template. GAPDH was used as the internal control to evaluate relative expression of $\mathrm{HO}-1, \mathrm{Bcl}-$ 2, and Bax. PCR amplification was conducted using specific primers (Bioneer, Daejeon, Korea), as reported previously [32]. The primer sequences are provided in Supplementary Table 1 of the Supplementary Material available online at http://dx.doi.org/10.1155/2013/514095.

2.10. Caspase-3 Activity Assay. Caspase-3 activity was detected using a Colorimetric Caspase-3 Assay kit (SigmaAldrich), according to the manufacturer's protocol. Briefly, the reaction mixture (total volume, $200 \mu \mathrm{L}$ ) contained $5 \mu \mathrm{L}$ of cell lysate/tissue lysate and $5 \mu \mathrm{L}$ of caspase- 3 substrate (AcDEVD-pNA; final concentration, $200 \mu \mathrm{M}$ ) in assay buffer, and the assay was carried out in a 96-well plate. A control reaction mixture contained $5 \mu \mathrm{L}$ of cell lysate and $5 \mu \mathrm{L}$ of the specific caspase-3 inhibitor (Ac-DEVD-CHO; final concentration, $20 \mu \mathrm{M}$ ) in assay buffer and was used to account for nonspecific hydrolysis of the substrate. Both mixtures were incubated for $90 \mathrm{~min}$ at $37^{\circ} \mathrm{C}$, and emission and excitation absorbance wavelengths of 360 and $460 \mathrm{~nm}$, respectively.

2.11. Statistical Analyses. All data were analyzed using Graph Pad Prism version 5.01 (Graph Pad, Inc., La Jolla, CA, USA). All data are expressed as mean \pm standard error of at least three independent experiments performed in triplicate in the case of the in vitro or histological and histobiochemical experiments. The comparison of interest in the behavioral experiment was the effect of each treatment compared to control mice and MPTP-intoxicated mice versus gastrodin and MPTP intoxicated mice. The statistical analysis was performed with a one-way analysis of variance followed by Tukey's multiple comparison test. $P$ values $<0.05$ were considered statistically significant.

\section{Results}

3.1. Gastrodin Ameliorates MPP $P^{+}$-Induced Loss of Neuronal Cell Viability. Treatment of SH-SY5Y cells with $1 \mathrm{mM} \mathrm{MPP}^{+}$ alone for up to $48 \mathrm{~h}$ resulted in marked cell death as evaluated by the MTT assay. Cell viability improved significantly in a dose-dependent manner when the cells were pretreated with various concentrations of gastrodin $(1,5$, and $25 \mu \mathrm{M})$ for $4 \mathrm{~h}$ prior to adding $1 \mathrm{mM} \mathrm{MPP}{ }^{+}$. Gastrodin alone did not cause any significant cytotoxicity. When cell viability in serum-free conditions was defined as $100 \%$ survival, viability of cells treated with $1 \mathrm{mM} \mathrm{MPP}^{+}$decreased to $50.5 \pm 1.4 \%$. The viability of cells incubated with 1,5 , and $25 \mu \mathrm{M}$ gastrodin was $51.7 \pm 3.1 \%, 59.4 \pm 1.0 \%$, and $78.2 \pm 3.2 \%$ of the control, respectively (Figure $1(\mathrm{~A})$ ). SH-SY5Y cells treated for $48 \mathrm{~h}$ with $1 \mathrm{mM} \mathrm{MPP}{ }^{+}$showed morphological changes normally associated with cell death such as cell shrinkage and rounding up of cell bodies (Figure 1(B)). The $\mathrm{MPP}^{+}$-induced changes in cell morphology were attenuated by gastrodin. The cells showed no morphological changes when treated with gastrodin alone.

3.2. Antioxidant Activity of Gastrodin. The potential for gastrodin to quench free radicals such as DPPH, alkyl, hydroxyl, 


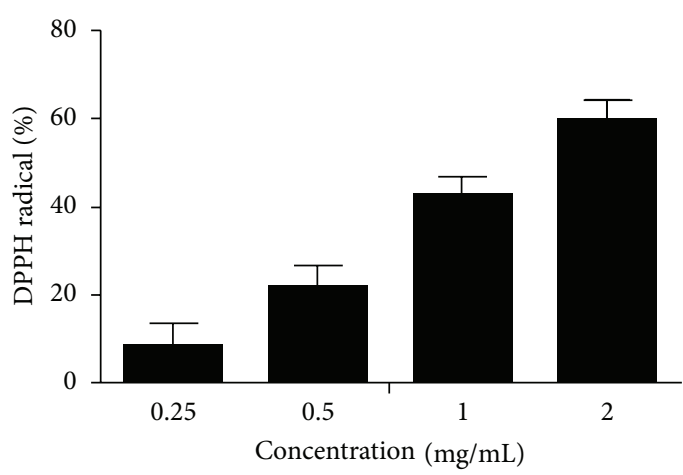

(a)

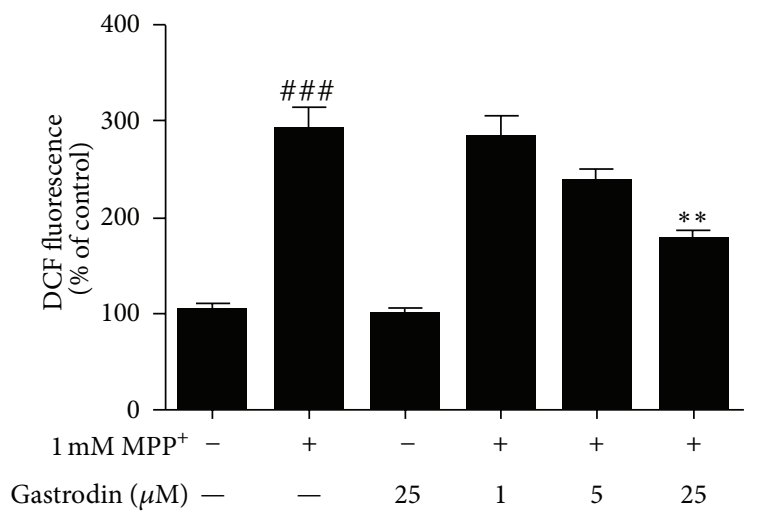

(c)

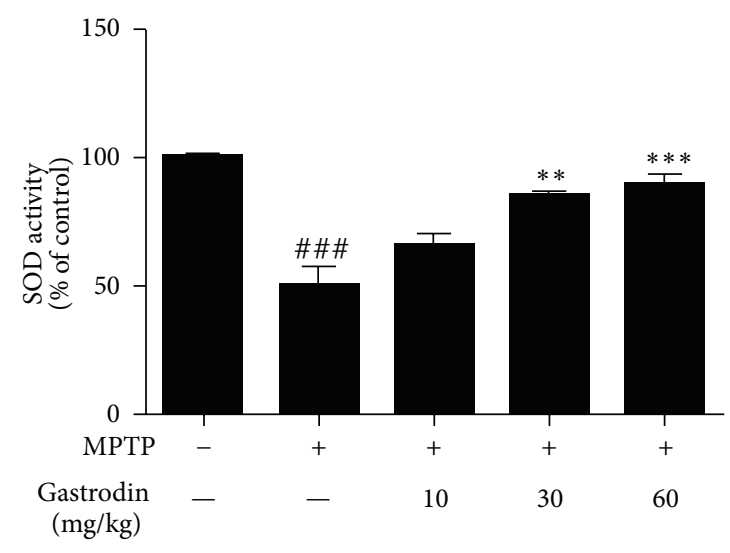

(e)

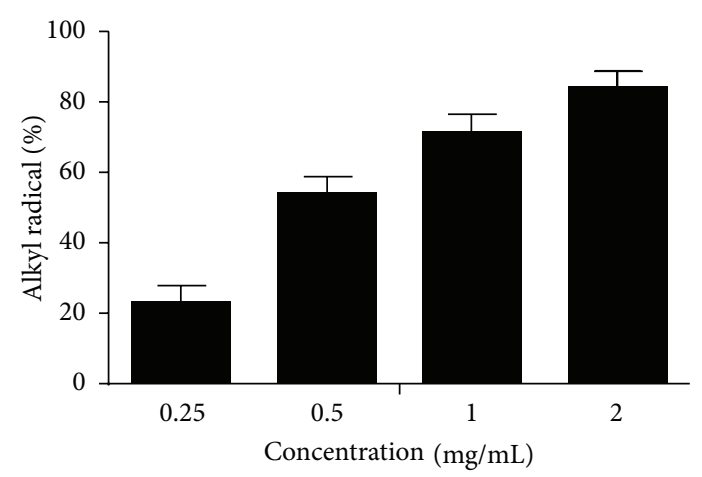

(b)

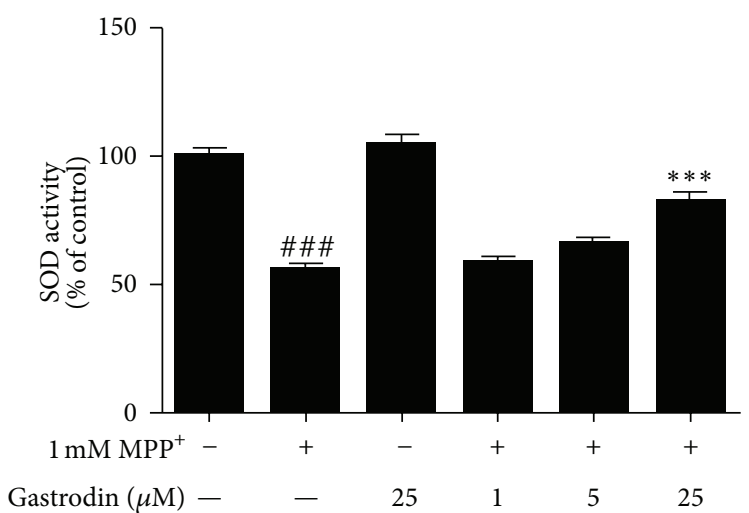

(d)

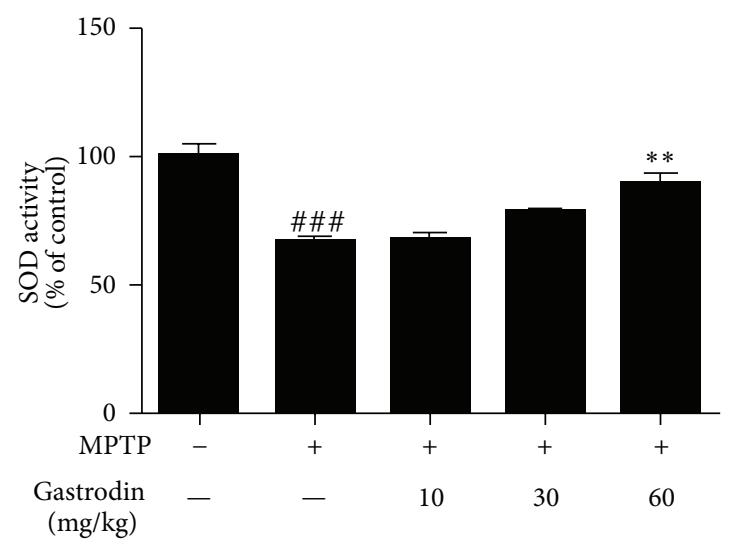

(f)

FIGURE 2: Effect of gastrodin on DPPH (a) and alkyl (b) free radical scavenging activities. Gastrodin prevented the ROS generation in $1 \mathrm{mM}$ $\mathrm{MPP}^{+}$-treated SH-SY5Y cells as measured by fluorometric analysis using DCFH-DA (c). Gastrodin augmented the MPP ${ }^{+}$- and MPTP-induced perturbation in superoxide dismutase (SOD) activity in SH-SY5Y cells (d), striatum (e), and SNpC (f), respectively. Data are percentages of values in the untreated control cultures and are means \pm standard errors of three independent experiments in triplicate. ${ }^{\# \#} P<0.001$ compared with the control group, ${ }^{* *} P<0.01$, and ${ }^{* * *} P<0.001$ compared with the $\mathrm{MPP}^{+}$-treated group (one-way analysis of variance followed by Tukey's post hoc test).

and superoxide radicals was investigated using ESR spectroscopy. DPPH is a stable free radical, accepts an electron or hydrogen radical to become a stable diamagnetic molecule, and has been used to evaluate free radical scavenging activity of natural antioxidants. The capacity of gastrodin to scavenge DPPH was measured by ESR spectrometry. $\mathrm{DPPH}$ radical scavenging activity of gastrodin increased in a dose-dependent manner with an $\mathrm{IC}_{50}$ value of $1.32 \pm$ $0.04 \mathrm{mg} / \mathrm{mL}$ (Figure 2(a)). The alkyl radical spin adduct of the 4-POBN/free radical was generated from $\mathrm{AAPH}$ at $37^{\circ} \mathrm{C}$ for $30 \mathrm{~min}$, and a decrease in the ESR signals was observed with increasing gastrodin doses. Alkyl radical scavenging activity of gastrodin $(0.25,0.5,1$, and $2 \mathrm{mg} / \mathrm{mL})$ was $22.96 \%$, $53.81 \%, 71.36 \%$, and $83.51 \%$, respectively, with an $\mathrm{IC}_{50}$ value 
of $0.49 \pm 0.01 \mathrm{mg} / \mathrm{mL}$ (Figure 2(b)). Gastrodin produced a weak nonsignificant scavenging effect on hydroxyl and superoxide radicals (data not shown). These results provide firm evidence of the significant antioxidant effects of gastrodin, particularly on DPPH and alkyl radical scavenging activities. We measured ROS generation in $1 \mathrm{mM}$ $\mathrm{MPP}^{+}$-treated cells by fluorometric analysis using DCFHDA. Cells exposed to $\mathrm{MPP}^{+}$displayed an obvious increase in DCF fluorescence at time-dependent when compared to the control cultures. The DCF fluorescence in cells exposed to $1 \mathrm{mM} \mathrm{MPP}^{+}$at $24 \mathrm{~h}$ was $290.4 \pm 40.6 \%$ higher than that of the control group. However, treatment with gastrodin effectively reduced the ROS generation and the suppressing effects strengthened with the increase of concentration of gastrodin (Figure 2(c)). Furthermore, we investigated SOD activity in $\mathrm{MPP}^{+} / \mathrm{MPTP}$ model in SH-SY5Y cell and mouse, respectively. $\mathrm{MPP}^{+} / \mathrm{MPTP}$ displayed perturbations in the activities of SOD. Pretreatment with gastrodin augmented the activities of SOD in the SH-SY5Y cells (Figure 2(d)), striatum (Figure 2(e)), and SNpC (Figure 2(f)).

\subsection{Gastrodin Attenuates MPTP-Induced Neurodegeneration:} TH and GFAP Immunoblots and Immunohistochemistry. TH, a marker of dopamine activity and GFAP, an astrocyte protein marker, were evaluated. The GFAP protein plays a significant role in the interactions of astrocytes with other cells that are required for the formation and maintenance of myelin. Additionally, GFAP may help to maintain the protective blood brain barrier that can only be crossed by certain solutes of $50-52 \mathrm{kDa}$ [33]. Due to these factors, GFAP has received much attention as a proposed biomarker in studies of central nervous system diseases [34, 35]. The density of GFAPpositive astrocytes significantly increases and is negatively correlated with the severity of dopamine neuron depletion [36]. Gastrodin restored decreased and increased expression of TH and GFAP, respectively, in MPTP-intoxicated mice (Figure 3(a)). Furthermore, these results were also reflected in immunoblot analysis, and gastrodin was found to be effective in restoring TH levels (Figures 3(b) and 3(c)) and GFAP expression (Figures 3(d) and 3(e)) in SNpC and striatum, respectively.

\subsection{Gastrodin Affects Bcl-2 and Bax Expression and Suppresses} $\mathrm{MPP}^{+} / \mathrm{MPTP}$ Induced Caspase-3 Activation. One of the main mechanisms involved in the induction of the mitochondrial apoptotic pathway is a decrease in Bcl-2 levels or, alternatively, an increase in Bax levels. The Bcl-2 family plays a pivotal role in cellular apoptotic machinery [37]. Bcl-2 family members are involved in cell death processes; Bcl2 is an antiapoptotic protein and Bax exhibits proapoptotic activity [37, 38]. We investigated whether gastrodin had an effect on $\mathrm{Bcl}-2$ and $\mathrm{Bax}$ expression in $\mathrm{MPP}^{+}$-treated cells using expression analysis. As shown in Figure 4(a), Bax expression increased significantly in the $\mathrm{MPP}^{+}$-treated group compared with that in control cells, which was consistent with previous studies [39, 40]. However, gastrodin treatment suppressed Bax mRNA expression in a dose-dependent manner. In contrast, the level of $\mathrm{Bcl}-2$ in the $\mathrm{MPP}^{+}$-treated group decreased significantly compared with that in control cells, whereas Bcl-2 expression recovered following gastrodin treatment. The Bax/Bcl-2 ratio in cells exposed to $1 \mathrm{mM}$ $\mathrm{MPP}^{+}$increased 5.6 \pm 0.1 fold compared to that in the control group, whereas the ratio decreased in a dose-dependent manner in cells pretreated with 1,5 , and $25 \mu \mathrm{M}$ gastrodin, suggesting that gastrodin shifted the balance from proand antiapoptotic members towards cell survival. Gastrodin treatment alone did not significantly alter the Bax/Bcl-2 ratio (Figure 4(a)). Furthermore, we investigated whether gastrodin had an effect on Bax and Bcl-2 expression in MPTP-intoxicated mice using expression analysis. MPTPintoxicated mice showed increased Bax expression in both the striatum and $\mathrm{SNpC}$, in agreement with a report published previously [41]. However, prophylactic treatment with gastrodin suppressed Bax mRNA expression in the SNpC and striatum in a dose-dependent manner. In contrast, $\mathrm{Bcl}-2$ level in MPTP-intoxicated mice decreased significantly compared with that in the vehicle group, but prophylactic treatment with gastrodin recovered Bcl-2 expression dose dependently. The Bax/Bcl-2 ratio in MPTP-intoxicated mice increased significantly (\#\# $P<0.001$ versus vehicle group) compared to that in the vehicle group, whereas prophylactic treatment with gastrodin attenuated the $\mathrm{Bax} / \mathrm{Bcl}-2$ ratio in a dosedependent manner $\left({ }^{* * *} P<0.001\right.$ at 30 and $\left.60 \mathrm{mg} / \mathrm{kg}\right)$ in the SNpC (Figure $4(\mathrm{c}))$ and $\left({ }^{*} P<0.05\right.$ at $10 \mathrm{mg} / \mathrm{kg},{ }^{* * *} P<0.001$ at 30 and $60 \mathrm{mg} / \mathrm{kg}$ ) in the striatum (Figure 4(d)), suggesting that the gastrodin pretreatment shifted the balance from proand antiapoptotic members towards cell survival. Caspase3 is a crucial biomarker of neuronal apoptosis that also acts as an apoptotic executor [42]. Treatment with $1 \mathrm{mM} \mathrm{MPP}$ markedly increased caspase- 3 activity, but adding gastrodin attenuated $\mathrm{MPP}^{+}$-induced caspase-3 expression to $356.53 \pm$ $22.27 \%, 285.66 \pm 24.71 \%$, and $171.12 \pm 16.37 \%$, respectively, in SH-SY5Y cells in a dose-dependent manner (Figure 4(b)). Furthermore, caspase- 3 activity showed marked increases in the SNpC and striatum of MPTP intoxicated mice (274.82 \pm $28.54 \%$ and $219.63 \pm 10.37 \%$, resp.). Gastrodin pretreatment dose-dependently attenuated MPTP induced caspase- 3 activity to $247.40 \pm 28.82 \%, 167.04 \pm 21.43 \%$, and $92.23 \pm 12.75 \%$, at 10,30 , and $60 \mathrm{mg} / \mathrm{kg}$, respectively, in the SNpC (Figure 4(e)) and to $130.65 \pm 21.11 \%, 96.71 \pm 11.03 \%$, and $88.57 \pm$ $7.53 \%$, at 10,30 , and $60 \mathrm{mg} / \mathrm{kg}$, respectively, in the striatum (Figure 4(f)).

3.5. Gastrodin Suppresses MPP $/ M P T P-I n d u c e d$ PARP Proteolysis. Caspase-3 also plays a major role in PARP cleavage during early apoptosis in many different cell lines $[43,44]$. A previous study reported that $\mathrm{MPP}^{+}$induces increases in PARP proteolysis at $48 \mathrm{~h}$ when compared to control cultures [45]. PARP cleavage to an $85 \mathrm{kDa}$ fragment was detected using a polyclonal antibody against full-length PARP (116 kDa), as well as cleaved PARP fragments ( $85 \mathrm{kDa})$. PARP proteolysis was enhanced significantly following treatment with $1 \mathrm{mM} \mathrm{MPP}$, but gastrodin concentrations of 1 , 5 , and $25 \mu \mathrm{M}$ attenuated $\mathrm{MPP}^{+}$-induced PARP proteolysis in a dose-dependent manner (Figure 5(a)). PARP cleavage is another hallmark of apoptosis $[44,46]$. Therefore, we further 


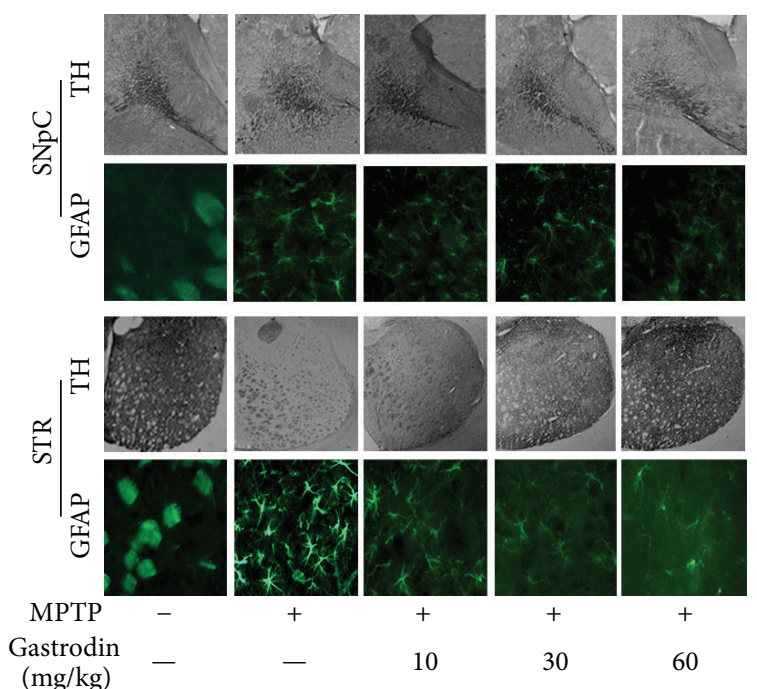

(a)
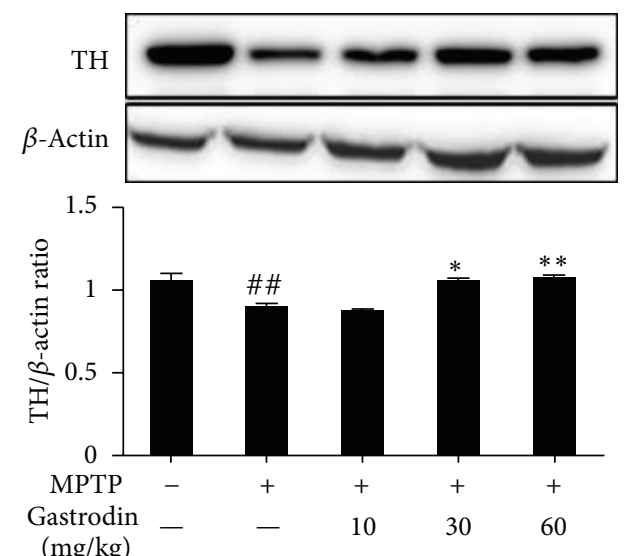

$(\mathrm{mg} / \mathrm{kg})$

(c)

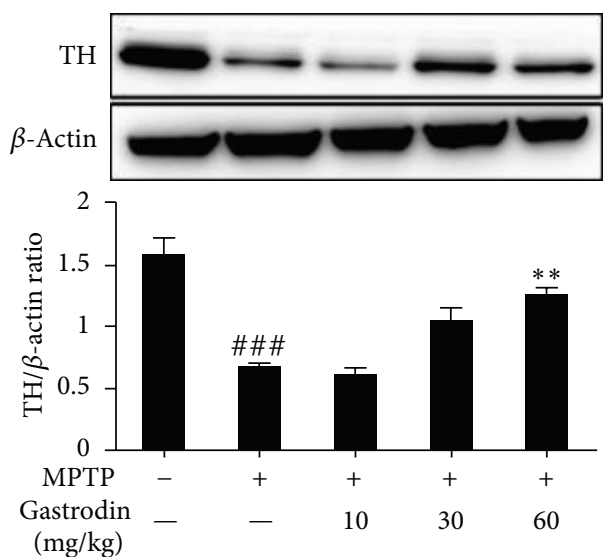

(b)

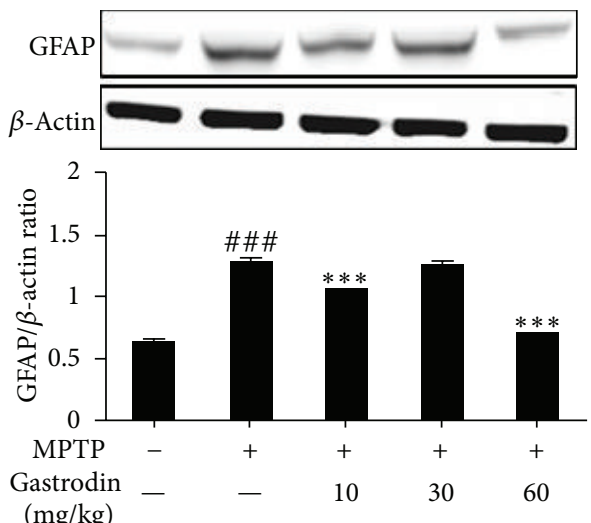

(d)
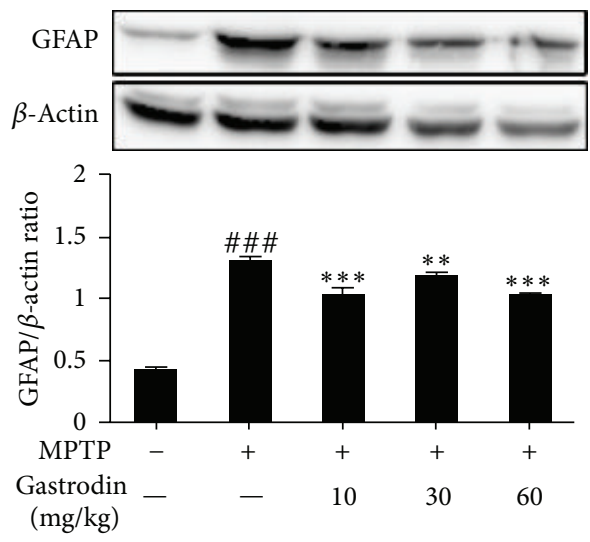

(e)

FIGURE 3: Protective effects of gastrodin against MPTP in the mouse substantia nigra pars compacta (SNpC) and striatum. Gastrodin was administered for 15 days at the respective doses, and MPTP was administered for the last 5 days of gastrodin treatment. All groups except the vehicle group received injections of $30 \mathrm{mg} / \mathrm{kg} /$ day MPTP for 5 days. Mice were anesthetized for the immunohistochemical study 7 days after MPTP intoxication and after performing the behavioral experiment. Glial fibrillary acidic protein (GFAP) immunofluorescence and immunohistochemistry for tyrosine hydroxylase (TH) were performed in the SNpC and striatum (a). Gastrodin protected against changes in TH and GFAP expression in the SNpC ((b) and (d)) and striatum ((c) and (e)) after MPTP intoxication. TH and GFAP protein levels in the SNpC and striatum were assessed by Western blot analysis. Bar graphs show quantitative data for TH and GFAP signals that are normalized to the $\beta$-actin signal ( $n=4-5$ per group). Values are mean \pm standard error $\left({ }^{\# \#} P<0.01,{ }^{\# \# \#} P<0.001\right.$ versus vehicle group) and $\left({ }^{*} P<0.05\right.$, ${ }^{* *} P<0.01$, and ${ }^{* * *} P<0.001$ versus MPTP group). 


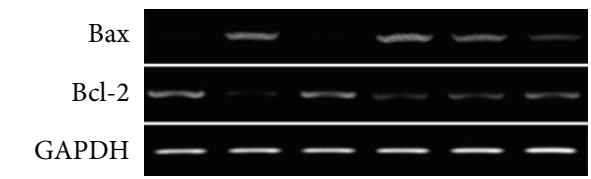

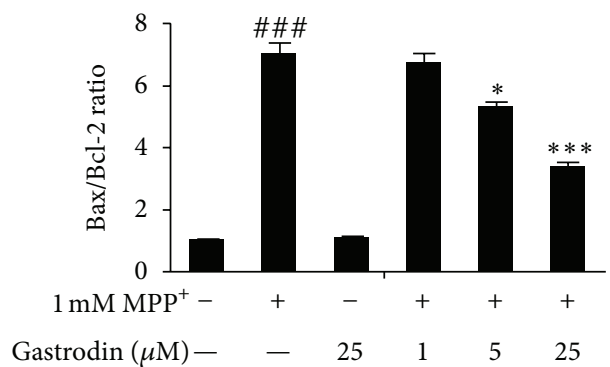

(a)
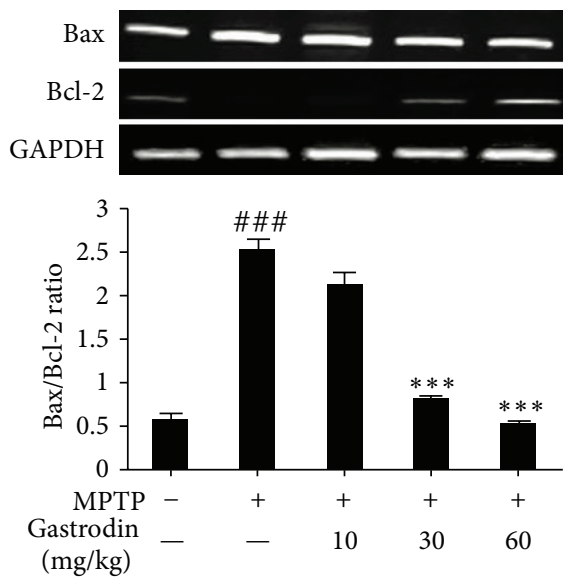

(c)

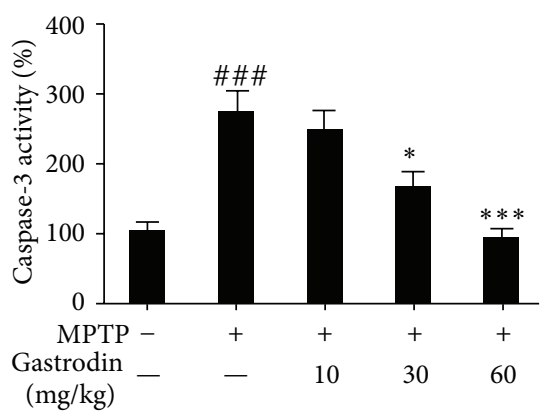

(e)

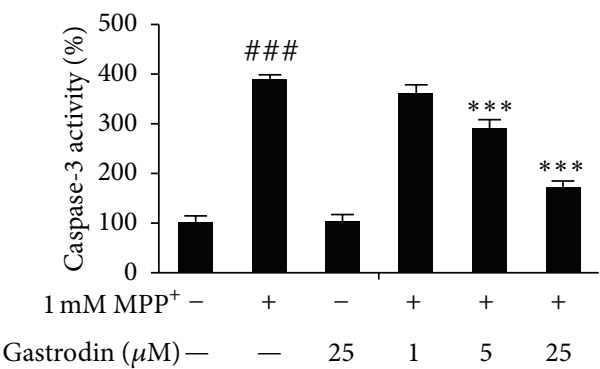

(b)

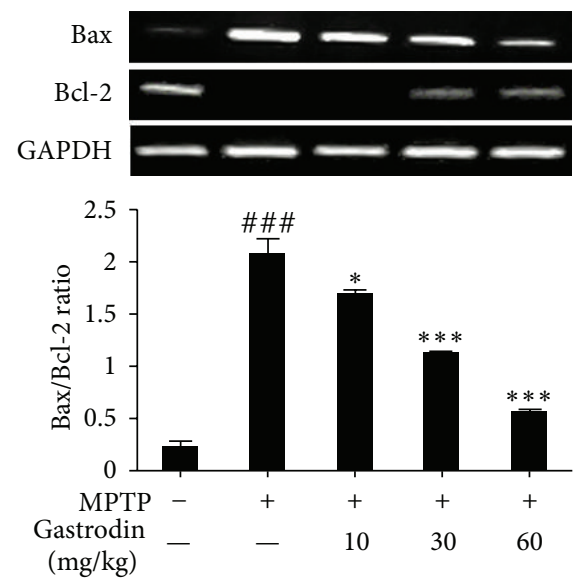

(d)

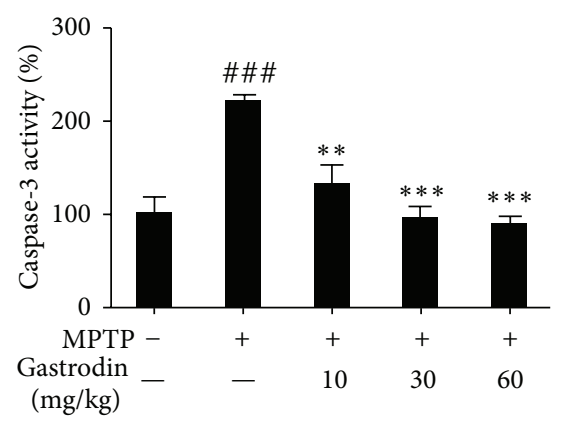

(f)

FIGURE 4: Effects of gastrodin on Bax and Bcl-2 mRNA expression and caspase-3 activity in SH-SY5Y cells and animal tissue treated with MPTP. Bax and Bcl-2 levels were quantified in SH-SY5Y cells by densitometric analysis (a) and in the substantia nigra pars compacta (SNpC) (c) and striatum (d) with their respective Bax/Bcl-2 ratios. Gastrodin inhibited the $\mathrm{MPP}^{+}$- and MPTP-induced increase in caspase-3 activity in SH-SY5Y cells (b), SNpC (e), and striatum (f), respectively. Data are from three independent experiments performed in triplicate. Values are mean \pm standard error ( ${ }^{\# \#} P<0.001$ versus vehicle group) and $\left({ }^{*} P<0.05,{ }^{* *} P<0.01\right.$, and ${ }^{* * *} P<0.001$ versus MPP $/ \mathrm{MPTP}^{+}$group).

examined PARP cleavage in MPTP-intoxicated mice and the effect of gastrodin on PARP cleavage. MPTP-intoxicated mice showed cleaved PARP ( ${ }^{\# \# \# ~} P<0.001$ versus vehicle group), but gastrodin pretreatment attenuated PARP cleavage in the SNpC (Figure $5(\mathrm{~b}))\left({ }^{* * *} P<0.001\right.$ versus MPTP group) and striatum (Figure $5(\mathrm{c}))\left({ }^{* * *} P<0.001\right.$ versus MPTP group).
3.6. Gastrodin Shows Neuroprotective Effects against MPTP Toxicity in a Mouse PD Model: Pole and Rotarod Tests. We performed the pole and rotarod tests to evaluate motor deficits and bradykinesia, respectively, in MPTP-intoxicated mice. The pole test results showed that the T-turn and TLA time were prolonged significantly $\left({ }^{\# \#} P<0.001\right.$ versus 


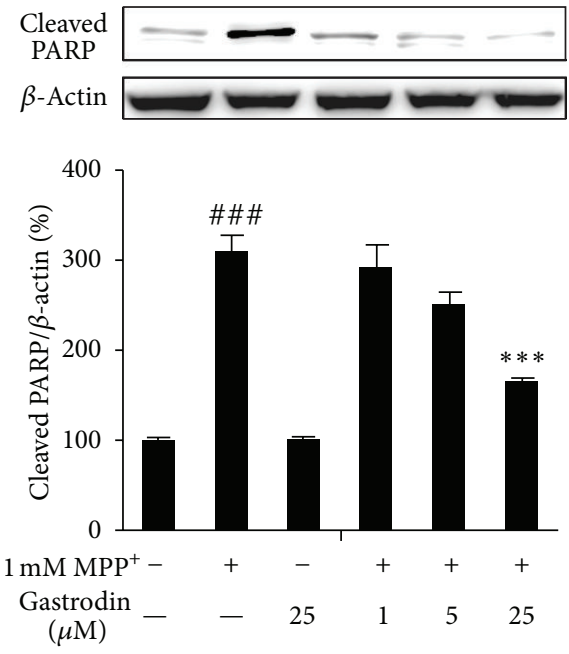

(a)
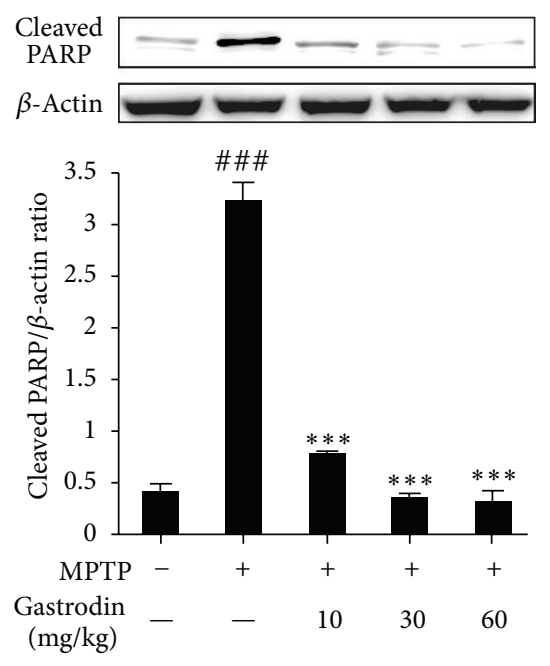

(b)
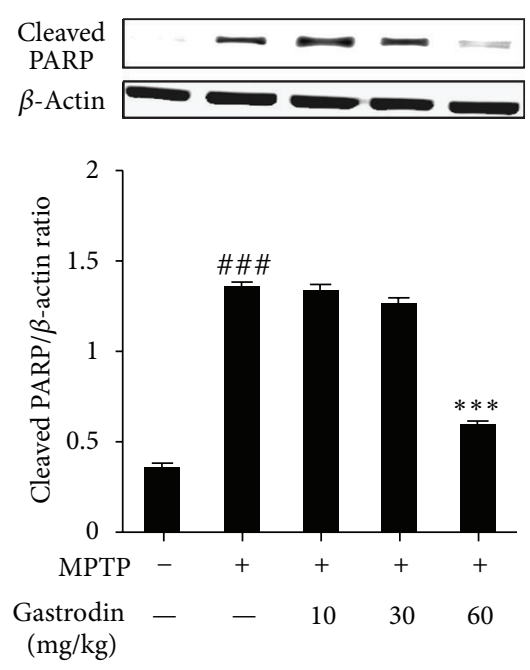

(c)

FIGURE 5: Gastrodin prevents poly(ADP-ribose) polymerase (PARP) cleavage against MPP ${ }^{+}$in SH-SY5Y cells (a), the substantia nigra pars compacta (SNpC) (b), and striatum (c) after MPTP treatment. PARP protein levels were assessed by Western blot analysis in cells/animal tissues. Bar graphs show quantitative data for PARP signals that are normalized to the $\beta$-actin signal ( $n=3-4$ per group). Values are mean \pm standard error ( ${ }^{\# \# \#} P<0.01$ versus vehicle group) and $\left({ }^{* * *} P<0.001\right.$ and versus $\mathrm{MPP}^{+} / \mathrm{MPTP}$ group).

vehicle group) after subchronic MPTP treatment. Prophylactic treatment with gastrodin at $30 \mathrm{mg} / \mathrm{kg}\left({ }^{*} \mathrm{P}<0.05\right.$ versus MPTP group in the TLA and T-turn) and $60 \mathrm{mg} / \mathrm{kg}$ significantly $\left({ }^{* * *} P<0.001,{ }^{* *} P<0.01\right.$ versus MPTP group in TLA and T-turn, resp.) shortened the time to reach the platform. The $10 \mathrm{mg} / \mathrm{kg}$ gastrodin dose tended to shorten the T-turn and TLA, although the difference was not significant (Figures 6(a) and 6(b)). Thus, gastrodin prevented MPTP-induced bradykinesia. MPTP-intoxicated mice showed decreased performance on the rotarod test (\#\# $P<0.001$ versus vehicle group), but prophylactic treatment with gastrodin at 10,30 , and $60 \mathrm{mg} / \mathrm{kg}$ resulted in improved rotarod test performance $\left({ }^{* * *} P<0.001\right.$ versus MPTP group), suggesting that the initial lesions caused by MPTP can be prevented by prophylactic treatment with gastrodin (Figure 6(c)).

\section{Discussion}

In the present study, we provide evidence that gastrodin possessed neuroprotective effects in in vitro and in vivo $\mathrm{PD}$ models possibly by inhibiting oxidative stress and apoptosisinduced neuronal cell death. Oxidative stress is one of the etiologies that could induce neuronal damage in the parkinsonian brain and also modulate intracellular signaling [47]. We used ESR to evaluate free radical scavenging activity of gastrodin. The results showed that gastrodin was a powerful antioxidant with significant radical scavenging activity for DPPH and alkyl radicals. Moreover, the treatment of SHSY5Y cells with $\mathrm{MPP}^{+}$causes a significant accumulation of intracellular ROS and gastrodin pretreatment ameliorates this effect. In this study, the $\mathrm{MPP}^{+} / \mathrm{MPTP}$ group showed lower SOD activities in SH-SY5Y cells/animals tissue. These results indicate that $\mathrm{MPP}^{+} / \mathrm{MPTP}$ reduce the elimination of hydrogen peroxide and free radicals in the brain. Gastrodin pretreatment in the $\mathrm{MPP}^{+} / \mathrm{MPTP}$-induced group showed increased SOD activities. These results suggest that the elimination of superoxide anion was enhanced by gastrodin. Furthermore, HO-1, an inducible gene upregulated by oxidative stress, appears to be a component of cellular oxidative stress response [48]. HO-1 is induced by chemicals like $\mathrm{MPP}^{+} / \mathrm{MPTP}$ that produce oxidative stress. HO-1 is a stress responsive enzyme and part of the cell's natural defence mechanisms. In the present study, $\mathrm{MPP}^{+}$caused increased HO-1 expression at protein level in SH-SY5Y cells and gastrodin restored this effect. Furthermore, gastrodin also showed protection against elevated $\mathrm{HO}-1$ level at mRNA and protein levels in SNpC and striatum of MPTP-treated mice (Supplementary Figure 1).

Generation of ROS causes severe impairment at the cellular level, ultimately leading to neuronal death by apoptosis, which is linked with neurodegenerative disorders such as PD [49]. The Bcl-2 family of intracellular proteins are central regulators of caspase activation and oppose the antiand proapoptotic members. Commitment to apoptosis in response to diverse physiological cues and cytotoxic agents is governed by Bcl-2 family proteins [37]. Members of the Bcl2 family, such as Bcl-2, bind to Bax to form Bax:Bcl-2 heterodimers; hence, antagonizing Bax procell death properties [50]. In the present study, $\mathrm{MPP}^{+}$showed a profound effect on the expression of Bcl-2 family members in SH-SY5Y cells. Treatment with gastrodin significantly reduced expression of proapoptotic Bax and significantly increased expression of antiapoptotic Bcl-2 in a dose-dependent manner, thereby ameliorating the increased $\mathrm{MPP}^{+}$-induced $\mathrm{Bax} / \mathrm{Bcl}-2$ ratio in SH-SY5Y cells. Furthermore, the MPTP mice model 


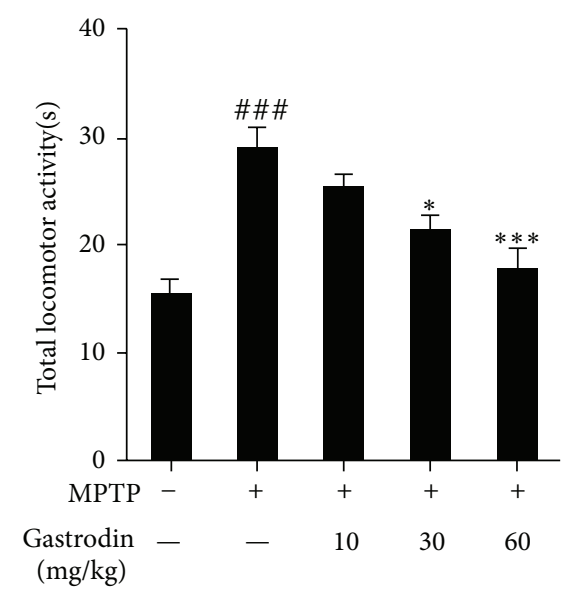

(a)

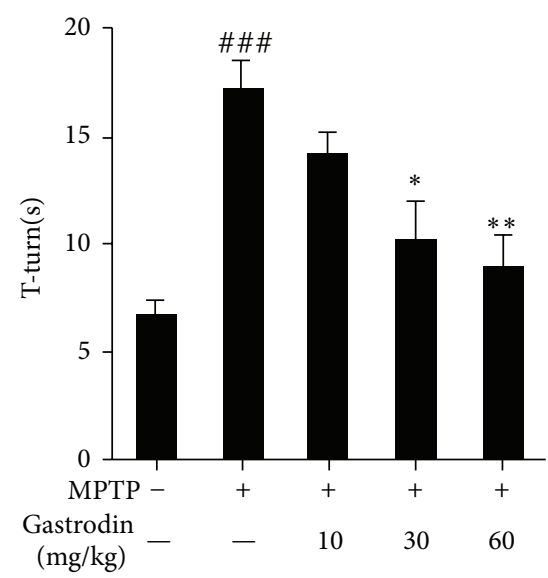

(b)

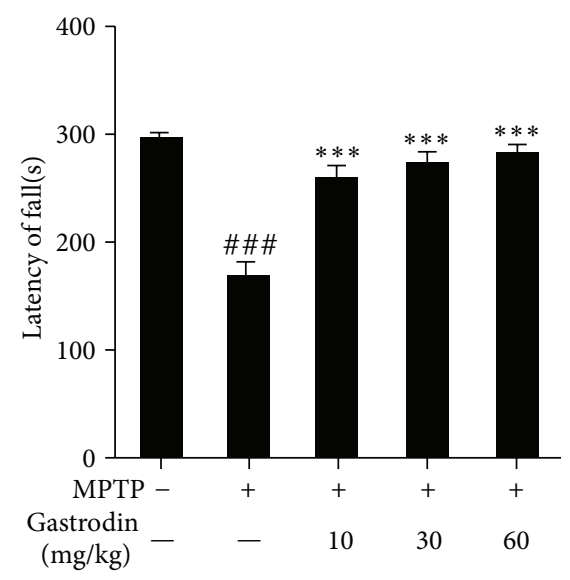

(c)

FIGURE 6: Protective effect of gastrodin against 1-methyl-4-phenyl-1,2,3,6-tetrahydropyridine- (MPTP-) induced behavioral dysfunction in a mouse model of Parkinson's disease. Vehicle or different doses (10,30, and $60 \mathrm{mg} / \mathrm{kg}$ ) of gastrodin were administered orally once per day for 15 days, and MPTP (30 mg/kg, i.p.) was injected during the last 5 days. Seven days after the last MPTP injection, the time to arrive at the floor (total locomotor activity) (a) and the time to turn completely downward (T-turn) (b) were recorded with a cutoff limit of $60 \mathrm{~s}$ for the pole test. Motor deficit was indicated by the latency of fall (c) during the rotarod test. Values are mean \pm standard error $\left({ }^{\# \#} P<0.001\right.$ versus vehicle group) and $\left({ }^{*} P<0.05,{ }^{* *} P<0.01\right.$, and ${ }^{* * *} P<0.001$ versus MPTP group).

provided the opportunity to explore the etiology of PD. Various MPTP regimens can be utilized to screen for possible neuroprotective effects. The subchronic MPTP mouse model is quite a popular regimen that results in apoptosis and depletes striatal dopamine by $40-50 \%$ in young adult C57BL/6 mice $[6,7,51]$. Apoptosis-induced neuronal death has been associated with the MPTP subchronic model [7]; accordingly, we determined Bax and Bcl-2 mRNA levels in the SNpC and striatum of MPTP-intoxicated mice. Bax mRNA was upregulated and Bcl-2 mRNA levels decreased in the SNpC and striatum of MPTP-intoxicated mice compared with those in the vehicle group. Prophylactic treatment with gastrodin reduced proapoptotic Bax expression and increased antiapoptotic Bcl-2 expression significantly and dose dependently.

Of the 12 caspases known in mammals, caspase- 3 has been associated with PD neuronal cell death. Caspase- 3 is a crucial biomarker of neuronal apoptosis that also acts as an apoptotic executor [42]. PARP, a downstream target of caspase-3, is an abundant nuclear enzyme and is normally involved in DNA repair, but extensive activation of PARP promotes cell death $[44,46]$. It is also known that $32-\mathrm{kDa}$ caspase- 3 is activated through cleavage into $12-\mathrm{kDa}$ and active $20 / 17-\mathrm{kDa}$ fragments by apoptotic signals, and that PARP is subsequently cleaved to an $85-\mathrm{kDa}$ fragment [52]. In our study, we found that gastrodin attenuated $\mathrm{MPP}^{+}$induced caspase- 3 activation and PARP cleavage in a dosedependent manner. Furthermore, MPTP-intoxicated mice also showed significant increases in caspase-3 activity in the $\mathrm{SNpC}$ and striatum, but various doses of gastrodin prevented caspase-3 activation and thereby might prevent neuronal damage. Gastrodin effectively attenuated MPTP-induced PARP cleavage in a dose-dependent manner, indicating that the protective effect of gastrodin is associated with inhibiting downstream apoptotic signaling pathways, which prevented PARP proteolysis.

Behavioral tests including the pole and rotarod tests were performed after 7 days of MPTP treatment, and mice were sacrificed for brain tissue and expression analyses after MPTP and/or gastrodin treatments. The pole test is a commonly used behavioral test in PD mouse models [53]. Gastrodin at doses of 10,30 , and $60 \mathrm{mg} / \mathrm{kg}$ for 15 days attenuated MPTP-induced bradykinesia on the pole test dose dependently. The rotarod test is sensitive to evaluate motor deficits caused by MPTP [31]. In our results, gastrodin protected against motor deficit caused by MPTP. In the histological analysis, TH immunoreactivity decreased in the SNpC and striatum following MPTP treatment, but prophylactic gastrodin treatment significantly reduced MPTP-induced dopaminergic neuronal damage in the SNpC and striatum dose dependently. GFAP is an intermediate astrocyte filament protein. GFAP-positive astrocyte density is negatively correlated with the severity of dopamine neuron depletion [36]. A recent study showed that astrocytes rapidly express GFAP following a subchronic MPTP dose [54]. Astrocytes respond to brain injury through a process termed "reactive gliosis," in which GFAP regulates the microenvironment, increases neuron survival, and promotes regeneration of neurites and functional recovery of the nervous system $[55,56]$. Several studies have shown that astrocytes protect neurons by synthesizing and releasing the free radical scavenger glutathione [57, 58]. In addition, activated astrocytes may stimulate microglial cells, which induce dopaminergic sprouting via the synthesis of neurotrophic factors [59]. MPTP treatment resulted in increased GFAP expression, but gastrodin at doses of 10,30 , and $60 \mathrm{mg} / \mathrm{kg}$ prevented gliosis dose dependently as shown in the immunoblot and immunofluorescence analyses. 
Moreover, gastrodin can cross the blood-brain barrier, enter the central nervous system, and protect against nerve lesions [60]. Gastrodin has been used as a safe and effective drug in the clinic for neurocognitive decline and refractory hypertension $[26,27]$. Taken together, the similarities between the MPTP model and PD suggest that the neuroprotective effects of gastrodin could be useful against PD and it might be developed as a future clinical candidate for PD.

\section{Conflict of Interests}

The authors declare that they have no conflict of interests.

\section{Authors' Contribution}

H. Kumar and I.-S. Kim contributed equally to this work.

\section{Acknowledgment}

This research was supported by the Basic Science Research Program through the National Research Foundation of Korea (NRF) funded by the Ministry of Education, Science and Technology (2011-0024940).

\section{References}

[1] W. Dauer and S. Przedborski, "Parkinson's disease: mechanisms and models," Neuron, vol. 39, no. 6, pp. 889-909, 2003.

[2] E. Hirsch, A. M. Graybiel, and Y. A. Agid, "Melanized dopaminergic neurons are differentially susceptible to degeneration in Parkinson's disease," Nature, vol. 334, no. 6180, pp. 345-348, 1988.

[3] B. R. Bloem, I. Irwin, O. J. S. Buruma et al., "The MPTP model: versatile contributions to the treatment of idiopathic Parkinson's disease," Journal of the Neurological Sciences, vol. 97, no. 2-3, pp. 273-293, 1990.

[4] K. Chiba, L. A. Peterson, and K. P. Castagnoli, "Studies on the molecular mechanism of bioactivation of the selective nigrostriatal toxin 1-methyl-4-phenyl-1,2,3,6-tetrahydropyridine," Drug Metabolism and Disposition, vol. 13, no. 3, pp. 342-347, 1985.

[5] K. F. Tipton and T. P. Singer, "Advances in our understanding of the mechanisms of the neurotoxicity of MPTP and related compounds," Journal of Neurochemistry, vol. 61, no. 4, pp. 11911206, 1993.

[6] V. Jackson-Lewis and S. Przedborski, "Protocol for the MPTP mouse model of Parkinson's disease," Nature Protocols, vol. 2, no. 1, pp. 141-151, 2007.

[7] N. A. Tatton and S. J. Kish, "In situ detection of apoptotic nuclei in the substantia nigra compacta of 1-methyl-4phenyl-1,2,3,6-tetrahydropyridine-treated mice using terminal deoxynucleotidyl transferase labelling and acridine orange staining," Neuroscience, vol. 77, no. 4, pp. 1037-1048, 1997.

[8] J. S. Choi, C. Park, and J. W. Jeong, "AMP-activated protein kinase is activated in Parkinson's disease models mediated by 1methyl-4-phenyl-1,2,3,6-tetrahydropyridine," Biochemical and Biophysical Research Communications, vol. 391, no. 1, pp. 147151, 2010.

[9] M. Gerlach, P. Riederer, H. Przuntek, and M. B. H. Youdim, "MPTP mechanisms of neurotoxicity and their implications for Parkinson's disease," European Journal of Pharmacology, vol. 208, no. 4, pp. 273-286, 1991.

[10] H. Kumar, S. V. More, S. D. Han, J. Y. Choi, and D. K. Choi, "Promising therapeutics with natural bioactive compounds for improving learning and memory-a review of randomized trials," Molecules, vol. 17, no. 9, pp. 10503-10539, 2012.

[11] D. J. Newman and G. M. Cragg, "Natural products as sources of new drugs over the 30 years from 1981 to 2010," Journal of Natural Products, vol. 75, no. 3, pp. 311-335, 2012.

[12] J. Liu and A. Mori, "Antioxidant and free radical scavenging activities of Gastrodia elata Bl. and Uncaria rhynchophylla (Miq.) jacks," Neuropharmacology, vol. 31, no. 12, pp. 1287-1298, 1992.

[13] J. H. Ha, S. M. Shin, S. K. Lee et al., "In vitro effects of hydroxybenzaldehydes from Gastrodia elata and their analogues on GABAergic neurotransmission, and a structureactivity correlation," Planta Medica, vol. 67, no. 9, pp. 877-880, 2001.

[14] C. L. Hsieh, S. Y. Chiang, K. S. Cheng et al., "Anticonvulsive and free radical scavenging activities of gastrodia data bl. in kainic acid-treated rats," American Journal of Chinese Medicine, vol. 29, no. 2, pp. 331-341, 2001.

[15] E. K. Ahn, H. J. Jeon, E. J. Lim, H. J. Jung, and E. H. Park, “Antiinflammatory and anti-angiogenic activities of Gastrodia elata Blume," Journal of Ethnopharmacology, vol. 110, no. 3, pp. 476482, 2007.

[16] K. Hu and J. H. Jeong, "A convergent synthetic study of biologically active benzofuran derivatives," Archives of Pharmacal Research, vol. 29, no. 6, pp. 476-478, 2006.

[17] B. W. Kim, S. Koppula, J. W. Kim et al., "Modulation of LPSstimulated neuroinflammation in BV-2 microglia by Gastrodia elata: 4-hydroxybenzyl alcohol is the bioactive candidate," Journal of Ethnopharmacology, vol. 139, no. 2, pp. 549-557, 2012.

[18] C. L. Hsieh, J. J. Lin, S. Y. Chiang et al., "Gastrodia elata modulated activator protein 1 via $\mathrm{c}$-Jun $\mathrm{N}$-terminal kinase signaling pathway in kainic acid-induced epilepsy in rats," Journal of Ethnopharmacology, vol. 109, no. 2, pp. 241-247, 2007.

[19] S. Park, D. S. Kim, and S. Kang, "Gastrodia elata Blume water extracts improve insulin resistance by decreasing body fat in diet-induced obese rats: vanillin and 4-hydroxybenzaldehyde are the bioactive candidates," European Journal of Nutrition, vol. 50, no. 2, pp. 107-118, 2011.

[20] J. W. Jung, B. H. Yoon, H. R. Oh et al., "Anxiolytic-like effects of Gastrodia elata and its phenolic constituents in mice," Biological and Pharmaceutical Bulletin, vol. 29, no. 2, pp. 261-265, 2006.

[21] Q. Niu, P. Niu, and S. He, "Effect of gastrodia elata on learning and memory impairment induced by aluminum in rats," Wei Sheng Yan Jiu, vol. 33, no. 1, pp. 45-48, 2004.

[22] C. R. Wu, M. T. Hsieh, S. C. Huang, W. H. Peng, Y. S. Chang, and C. F. Chen, "Effects of Gastrodia elata and its active constituents on scopolamine-induced amnesia in rats," Planta Medica, vol. 62, no. 4, pp. 317-321, 1996.

[23] J. N. Dai, Y. Zong, L. M. Zhong et al., "Gastrodin inhibits expression of inducible no synthase, cyclooxygenase-2 and proinflammatory cytokines in cultured LPS-Stimulated microglia via MAPK pathways," PLoS ONE, vol. 6, no. 7, Article ID e21891, 2011.

[24] W. Yong, T. R. Xing, S. Wang et al., "Protective effects of gastrodin on lead-induced synaptic plasticity deficits in rat hippocampus," Planta Medica, vol. 75, no. 10, pp. 1112-1117, 2009. 
[25] S. J. Yu, J. R. Kim, C. K. Lee et al., "Gastrodia elata blume and an active component, p-hydroxybenzyl alcohol reduce focal ischemic brain injury through antioxidant related gene expressions," Biological and Pharmaceutical Bulletin, vol. 28, no. 6, pp. 1016-1020, 2005.

[26] Z. Zhang, P. Ma, Y. Xu et al., "Preventive effect of gastrodin on cognitive decline after cardiac surgery with cardiopulmonary bypass: a double-blind, randomized controlled study," Journal of Huazhong University of Science and Technology, vol. 31, no. 1, pp. 120-127, 2011.

[27] Q. Zhang, Y. M. Yang, and G. Y. Yu, "Effects of gastrodin injection on blood pressure and vasoactive substances in treatment of old patients with refractory hypertension: a randomized controlled trial," Journal of Chinese Integrative Medicine, vol. 6, no. 7, pp. 695-699, 2008.

[28] Z. Datki, A. Juhász, M. Gálfi et al., "Method for measuring neurotoxicity of aggregating polypeptides with the MTT assay on differentiated neuroblastoma cells," Brain Research Bulletin, vol. 62, no. 3, pp. 223-229, 2003.

[29] F. Nanjo, K. Goto, R. Seto, M. Suzuki, M. Sakai, and Y. Hara, "Scavenging effects of tea catechins and their derivatives on 1,1- diphenyl-2-picrylhydrazyl radical," Free Radical Biology and Medicine, vol. 21, no. 6, pp. 895-902, 1996.

[30] N. Ogawa, Y. Hirose, and S. Ohara, "A simple quantitative bradykinesia test in MPTP-treated mice," Research Communications in Chemical Pathology and Pharmacology, vol. 50, no. 3, pp. 435-441, 1985.

[31] G. Rozas, E. López-Martín, M. J. Guerra, and J. L. LabandeiraGarcía, "The overall rod performance test in the MPTPtreated-mouse model of Parkinsonism," Journal of Neuroscience Methods, vol. 83, no. 2, pp. 165-175, 1998.

[32] M. Jin, B. W. Kim, S. Koppula et al., "Molecular effects of activated BV-2 microglia by mitochondrial toxin 1-methyl-4phenylpyridinium," Neurotoxicology, vol. 33, no. 2, pp. 147-155, 2012.

[33] F. C. A. Gomes, D. Paulin, and V. M. Neto, "Glial fibrillary acidic protein (GFAP): modulation by growth factors and its implication in astrocyte differentiation," Brazilian Journal of Medical and Biological Research, vol. 32, no. 5, pp. 619-631, 1999.

[34] C. S. Jung, C. Foerch, A. Schänzer et al., "Serum GFAP is a diagnostic marker for glioblastoma multiforme," Brain, vol. 130, no. 12, pp. 3336-3341, 2007.

[35] P. M. Kochanek, R. P. Berger, H. Bayir, A. K. Wagner, L. W. Jenkins, and R. S. B. Clark, "Biomarkers of primary and evolving damage in traumatic and ischemic brain injury: diagnosis, prognosis, probing mechanisms, and therapeutic decision making," Current Opinion in Critical Care, vol. 14, no. 2, pp. 135-141, 2008.

[36] P. L. McGeer, S. Itagaki, B. E. Boyes, and E. G. McGeer, "Reactive microglia are positive for HLA-DR in the substantia nigra of Parkinson's and Alzheimer's disease brains," Neurology, vol. 38, no. 8, pp. 1285-1291, 1988.

[37] S. Cory and J. M. Adams, "The BCL2 family: regulators of the cellular life-or-death switch," Nature Reviews Cancer, vol. 2, no. 9, pp. 647-656, 2002.

[38] K. L. O’Malley, J. Liu, J. Lotharius, and W. Holtz, “Targeted expression of BCL-2 attenuates $\mathrm{MPP}^{+}$but not 6-OHDA induced cell death in dopaminergic neurons," Neurobiology of Disease, vol. 14, no. 1, pp. 43-51, 2003.
[39] M. Gao, W. C. Zhang, Q. S. Liu, J. J. Hu, G. T. Liu, and G. H. Du, "Pinocembrin prevents glutamate-induced apoptosis in SHSY5Y neuronal cells via decrease of bax/bcl-2 ratio," European Journal of Pharmacology, vol. 591, no. 1-3, pp. 73-79, 2008.

[40] Y. F. Cheng, G. Q. Zhu, M. Wang et al., "Involvement of ubiquitin proteasome system in protective mechanisms of Puerarin to MPP+-elicited apoptosis," Neuroscience Research, vol. 63, no. 1, pp. 52-58, 2009.

[41] M. Vila, V. Jackson-Lewis, S. Vukosavic et al., "Bax ablation prevents dopaminergic neurodegeneration in the 1-methyl-4phenyl-1,2,3,6-tetrahydropyridine mouse model of Parkinson's disease," Proceedings of the National Academy of Sciences of the United States of America, vol. 98, no. 5, pp. 2837-2842, 2001.

[42] A. Hartmann, S. Hunot, P. P. Michel et al., "Caspase-3: a vulnerability factor and final effector in apoptotic death of dopaminergic neurons in Parkinson's disease," Proceedings of the National Academy of Sciences of the United States of America, vol. 97, no. 6, pp. 2875-2880, 2000.

[43] Y. A. Lazebnik, S. H. Kaufmann, S. Desnoyers, G. G. Poirier, and W. C. Earnshaw, "Cleavage of poly(ADP-ribose) polymerase by a proteinase with properties like ICE," Nature, vol. 371, no. 6495, pp. 346-347, 1994.

[44] D. A. Le, Y. Wu, Z. Huang et al., "Caspase activation and neuroprotection in caspase-3-deficient mice after in vivo cerebral ischemia and in vitro oxygen glucose deprivation," Proceedings of the National Academy of Sciences of the United States of America, vol. 99, no. 23, pp. 15188-15193, 2002.

[45] Y. Kitamura, T. Kosaka, J. I. Kakimura et al., "Protective effects of the antiparkinsonian drugs talipexole and pramipexole against 1-methyl-4-phenylpyridinium-induced apoptotic death in human neuroblastoma SH-SY5Y cells," Molecular Pharmacology, vol. 54, no. 6, pp. 1046-1054, 1998.

[46] M. Tewari, L. T. Quan, K. O’Rourke et al., "Yama/СРP32 $\beta$, a mammalian homolog of CED-3, is a CrmA-inhibitable protease that cleaves the death substrate poly(ADP-ribose) polymerase," Cell, vol. 81, no. 5, pp. 801-809, 1995.

[47] H. Kumar, H. W. Lim, S. V. More et al., "The role of free radicals in the aging brain and Parkinson's disease: convergence and parallelism," International Journal of Molecular Sciences, vol. 13, no. 8, pp. 10478-10504, 2012.

[48] M. D. Maines, "The heme oxygenase system: a regulator of second messenger gases," Annual Review of Pharmacology and Toxicology, vol. 37, pp. 517-554, 1997.

[49] E. Mohr, T. Mendis, and J. D. Grimes, "Late cognitive changes in Parkinson's disease with an emphasis on dementia," Advances in Neurology, vol. 65, pp. 97-113, 1995.

[50] Z. N. Oltvai, C. L. Milliman, and S. J. Korsmeyer, "Bcl-2 heterodimerizes in vivo with a conserved homolog, Bax, that accelerates programed cell death," Cell, vol. 74, no. 4, pp. 609619, 1993.

[51] N. Schmidt and B. Ferger, "Neurochemical findings in the MPTP model of Parkinson's disease," Journal of Neural Transmission, vol. 108, no. 11, pp. 1263-1282, 2001.

[52] D. W. Nicholson, A. Ali, N. A. Thornberry et al., "Identification and inhibition of the ICE/CED-3 protease necessary for mammalian apoptosis," Nature, vol. 376, no. 6535, pp. 37-43, 1995.

[53] K. Matsuura, H. Kabuto, H. Makino, and N. Ogawa, "Pole test is a useful method for evaluating the mouse movement disorder caused by striatal dopamine depletion," Journal of Neuroscience Methods, vol. 73, no. 1, pp. 45-48, 1997. 
[54] P. C. Chen, M. R. Vargas, A. K. Pani et al., "Nrf2-mediated neuroprotection in the MPTP mouse model of Parkinson's disease: critical role for the astrocyte," Proceedings of the National Academy of Sciences of the United States of America, vol. 106, no. 8, pp. 2933-2938, 2009.

[55] M. Vessal, C. B. Dugani, D. A. Solomon, W. McIntyre Burnham, and G. O. Ivy, "Might astrocytes play a role in maintaining the seizure-prone state?" Brain Research, vol. 1044, no. 2, pp. 190196, 2005.

[56] U. Wilhelmsson, E. A. Bushong, D. L. Price et al., "Redefining the concept of reactive astrocytes as cells that remain within their unique domains upon reaction to injury," Proceedings of the National Academy of Sciences of the United States of America, vol. 103, no. 46, pp. 17513-17518, 2006.

[57] R. Dringen, B. Pfeiffer, and B. Hamprecht, "Synthesis of the antioxidant glutathione in neurons: supply by astrocytes of CysGly as precursor for neuronal glutathione," Journal of Neuroscience, vol. 19, no. 2, pp. 562-569, 1999.

[58] J. Hirrlinger, J. B. Schulz, and R. Dringen, "Glutathione release from cultured brain cells: multidrug resistance protein 1 mediates the release of GSH from rat astroglial cells," Journal of Neuroscience Research, vol. 69, no. 3, pp. 318-326, 2002.

[59] P. E. Batchelor, G. T. Liberatore, J. Y. F. Wong et al., "Activated macrophages and microglia induce dopaminergic sprouting in the injured striatum and express brain-derived neurotrophic factor and glial cell line-derived neurotrophic factor," Journal of Neuroscience, vol. 19, no. 5, pp. 1708-1716, 1999.

[60] Q. Wang, G. Chen, and S. Zeng, "Distribution and metabolism of gastrodin in rat brain," Journal of Pharmaceutical and Biomedical Analysis, vol. 46, no. 2, pp. 399-404, 2008. 


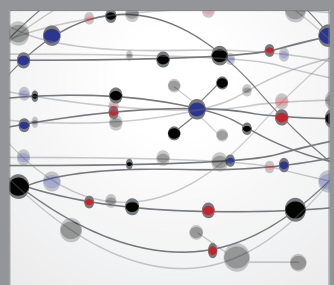

The Scientific World Journal
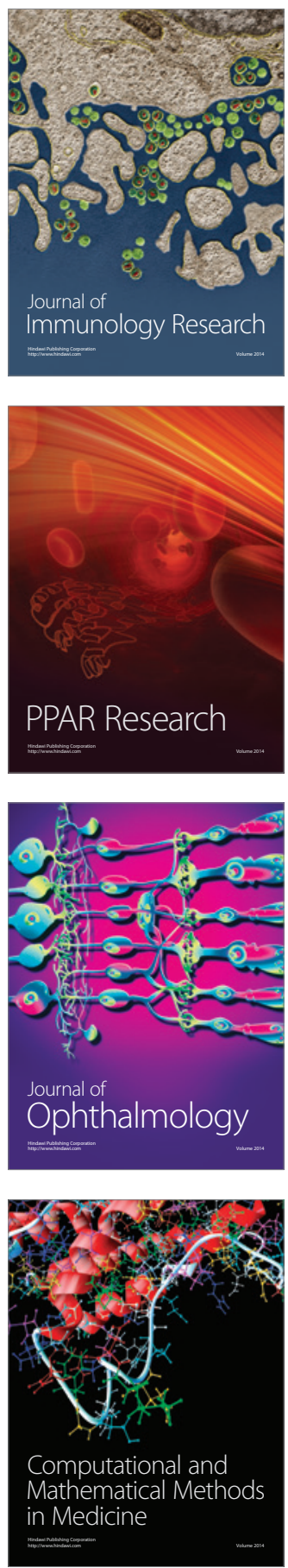

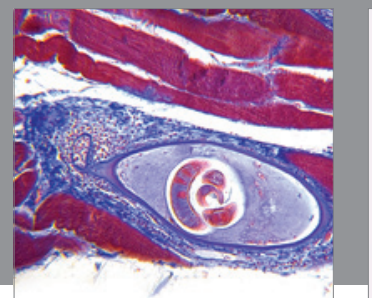

Gastroenterology

Research and Practice
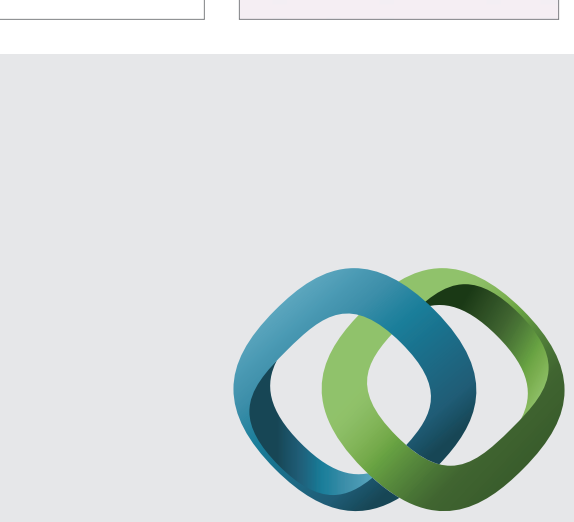

\section{Hindawi}

Submit your manuscripts at

http://www.hindawi.com
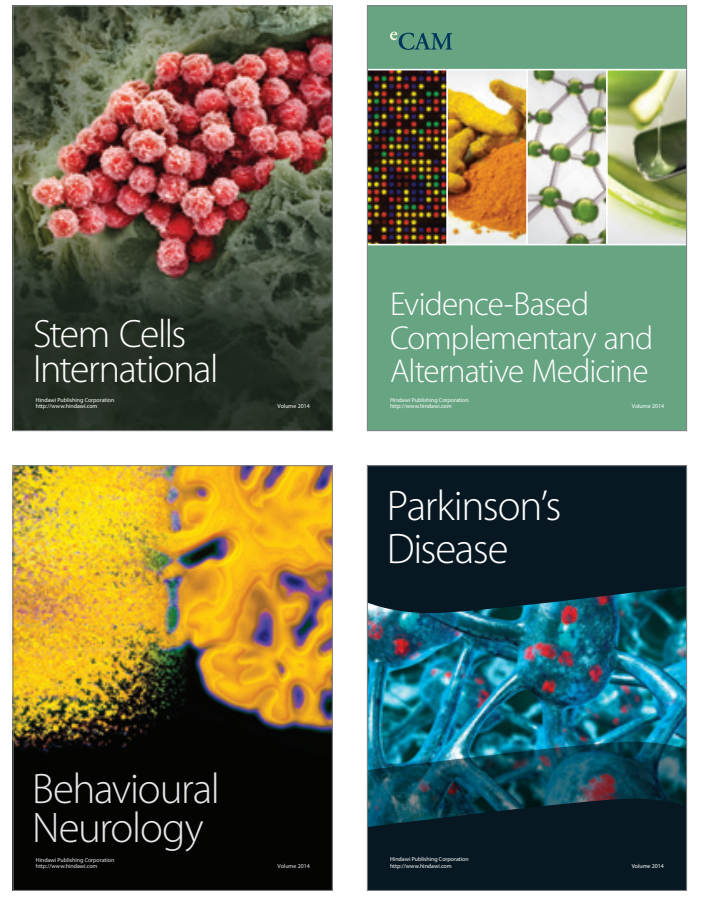
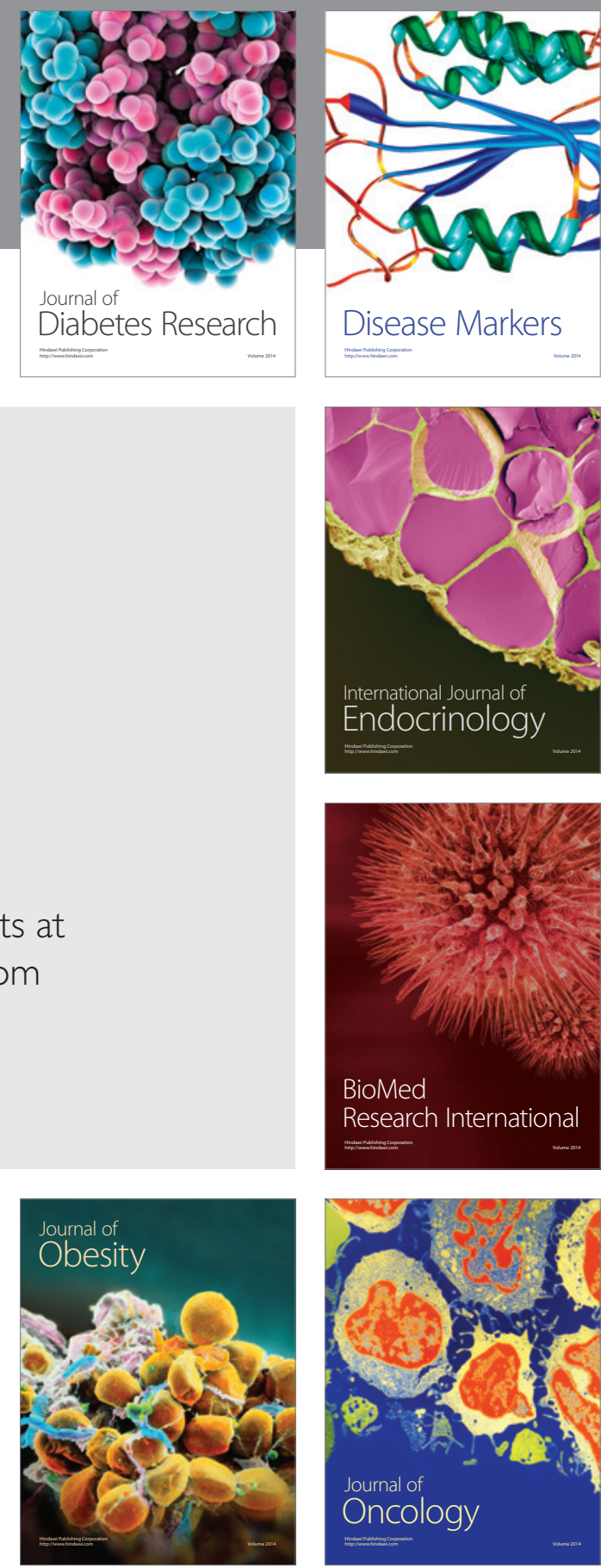

Disease Markers
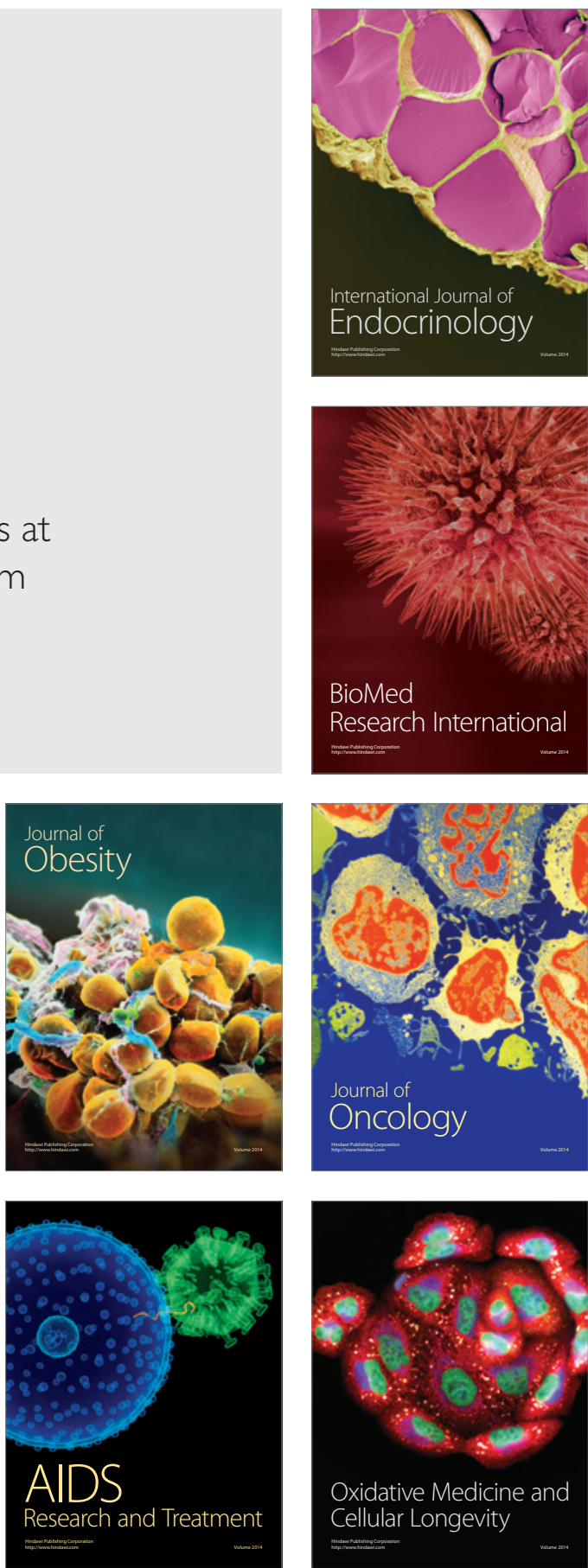